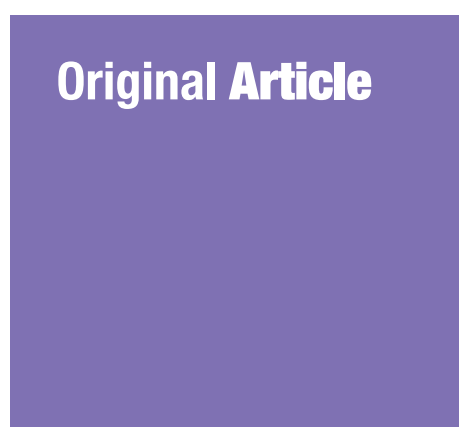

Submitted: 4 Aug 2015

Accepted: 18 Apr 2017

Online: 30 Jun 2017

\section{Comparing Lavage of the Peritoneal Cavity with Lidocaine, Bupivacaine and Normal Saline to Reduce the Formation of Abdominal Adhesion Bands in Rats}

\author{
Hossein Parsa ${ }^{1}$, Hengameh Saravani ${ }^{1}$, Fatemeh Sameel-Rad ${ }^{2}$, \\ Marjan NASIRI ${ }^{3}$, Zahra FARAHANINIK ${ }^{1}$, Amirhossein RAHMANI ${ }^{1}$
}

\author{
Department of Surgery, Velayat Clinical Research Development Unit, \\ Qazvin University of Medical Sciences, Shahid Bahonar Blvd, 3419759811 \\ Qazvin, Iran \\ $2 \quad$ Metabolic Diseases Research Center, Qazvin University of Medical \\ Sciences, Shahid Bahonar Blvd, 3419759811 Qazvin, Iran \\ 3 Department of Pharmacology, Qazvin University of Medical Sciences, \\ Shahid Bahonar Blvd, 3419759811 Qazvin, Iran
}

To cite this article: Parsa H, Saravani H, Sameei-Rad F, Nasiri M, Farahaninik Z, Rahmani A. Comparing lavage of the peritoneal cavity with lidocaine, bupivacaine and normal saline to reduce the formation of abdominal adhesion bands in rats. Malays J Med Sci. 2017;24(3):26-32. https://doi.org/10.21315/mjms2017.24.3.4

To link to this article: https://doi.org/10.21315/mjms2017.24.3.4

\title{
Abstract
}

Background: Intra-abdominal adhesions are fibrous bands that develop after abdominal surgery or inflammation and cause mortality and morbidity following surgeries. This study aimed to assess the effects of bupivacaine, saline and two doses of lidocaine, after peritoneal lavage and to compare their effects in reducing abdominal adhesions in rat.

Methods: In a blinded, randomised, placebo-controlled clinical trial, 50 female rats were anaesthetised and the parietal peritoneum was scratched to induce punctate bleeding. The rats were randomly assigned to five groups: saline, lidocaine $2 \%$ (3 and $6 \mathrm{mg} / \mathrm{kg}$ ), bupivacaine $0.25 \%$ $(2 \mathrm{mg} / \mathrm{kg}$ ) and control (no irrigation). The peritoneal cavity was irrigated with the appropriate solution during laparotomy. Two weeks later, re-laparotomy was performed. The quantity, quality, severity and scores of adhesions were recorded and compared.

Results: The quantity and quality of adhesions were significantly higher in the control group than in the lidocaine $(6 \mathrm{mg} / \mathrm{kg})$ and bupivacaine groups. The quality of the adhesions was higher in the normal saline group than in the lidocaine $(6 \mathrm{mg} / \mathrm{kg})$ and bupivacaine groups. The severity of adhesions between the lidocaine 3 and $6 \mathrm{mg} / \mathrm{kg}$ groups and between the lidocaine $3 \mathrm{mg} /$ $\mathrm{kg}$ and saline groups was lower than that in the control group.

Conclusion: Using lidocaine $(6 \mathrm{mg} / \mathrm{kg})$ and bupivacaine lavage in first laparotomy reduces abdominal peritoneal obstruction because of the formation of adhesion bands.

Keywords: adhesion, lidocaine, peritoneal lavage

\section{Introduction}

The chance of having a surgery is increasing with the rise in life expectancy. An overall rise in the numbers of surgeries has led to an increase in the risk of developing post-surgical adhesions, which proves the importance of this issue. Intra-abdominal adhesions can lead to severe complications during and after surgeries (1). This has led to the search for a method to prevent intra-abdominal adhesions (2-10). In physiological conditions, fibrin exudates accelerate the healing process in damaged tissues. However, in pathological conditions, 
Original Article | Effect of lidocaine with bupivacaine on adhesion band

this fibrin tissue might lead to the formation of unwanted fibrous bands (6). Inflammatory reactions that can result following surgery or bacterial infections can lead to the formation of fibrin deposits in the intra-peritoneal cavity, which in turn leads to the formation of intraabdominal adhesions (7). Avoiding excessive tissue damage during surgery, preventing infections and cytokine responses may reduce the severity of inflammation andthe risk of adhesions (11). Many factors can decrease the adhesion rate after abdominal surgery. Hypothermia induction decreases postoperative intra-abdominal adhesion (12). Other factors such as orally administered simvastatin, omega 3 fatty acids $(13,14)$, intraperitoneal administration of losartan plus atorvastatin (15), and using poly(lactic-co-glycolic acid) nanofibers between the abdominal wall and the peritoneum (16) reduces postoperative intra-abdominal adhesions. In one study, a non-steroidal antiinflammatory drug (NSAID) called Tenoxicam reduced the formation of fibrin and prevented the formation of adhesions following abdominal surgery in rats. This showed that Tenoxicam can be effective in preventing the formation of adhesions (3). In a similar study, heparin led to positive results (8). However, because of a significantly increased risk of bleeding associated with heparin, the researchers suggested using low-molecular-weight heparin instead of standard heparin $(9,10)$. Further studies showed that fresh acellular fibrin bridges can be destroyed with fibrinolytic enzymes, but if fibrin bridges are surrounded by cells and connective tissues, fibrinolytic enzymes cannot penetrate into the bridges, and this increases the risk of the formation of adhesions (17). Local anaesthetic drugs have recently been considered in this field. In a few studies using these drugs, satisfactory results have been reported $(18,19)$. However, there is clearly a lack of adequate information in this area and further studies are needed to confirm the results and optimal usage of other drugs. The purpose of this study was to compare the effects of peritoneal irrigation with lidocaine $3 \mathrm{mg} / \mathrm{kg}$, lidocaine $6 \mathrm{mg} / \mathrm{kg}$, bupivacaine $0.25 \%$ and saline in reducing intra-abdominal adhesions in rats following laparotomy.

\section{Materials and Methods}

After approval of the plan by the Research Department of Qazvin University of Medical Sciences, 50 non-pregnant female Wistar albino rats weighing $250 \mathrm{~g}-320 \mathrm{~g}$ were included in a blinded, randomised, placebo-controlled preclinical trial. Rats were brought to the laboratory 24 hours before the experiment and allowed to eat and drink freely before the operation. All guidelines and recommendations of the European Communities Council Directive of 24 November 1986 (86/609/EEC) were followed for minimising the number of rats used and their suffering. Following general anaesthesia using intramuscular ketamine/xylazine (6o $\mathrm{mg} / \mathrm{kg}$ and $6 \mathrm{mg} / \mathrm{kg}$, respectively) as described previously (20), the rats had a laparotomy with a $5 \mathrm{~cm}$ midline incision. Then, to stimulate the formation of intra-abdominal adhesions, using the method described by Liebman et al. (4), parts of the antral and dorsal cecum and its adjacent abdominal wall were scratched with a sterile gauze to induce punctate bleeding. Based on a random numbers table, then the rats were divided into five groups. In the control group, the laparotomy incision was closed without any irrigation $(n=10)$. In the saline group, the peritoneal cavity was irrigated with $5 \mathrm{ml}$ of saline before closing the laparotomy incision $(n=10)$. Lidocaine $2 \%(3 \mathrm{mg} / \mathrm{kg})$ group: Peritoneal cavity was irrigated with $3 \mathrm{mg} /$ $\mathrm{kg}$ of Lidocaine $2 \%$ before closing laparotomy incision $(n=10)$. Lidocaine $2 \%(6 \mathrm{mg} / \mathrm{kg})$ group: Peritoneal cavity was irrigated with $6 \mathrm{mg} / \mathrm{kg}$ of Lidocaine $2 \%$ before closing laparotomy incision $(n=10)$. Bupivacaine group: Peritoneal cavity was irrigated with $2 \mathrm{mg} / \mathrm{kg}$ of bupivacaine $0.25 \%$ ( $2 \mathrm{mg} / \mathrm{kg}, n=10$ ) before closing the laparotomy incision. Doses of each local anaesthetic drug were calculated according to the maximum permissible infiltration dose according to the guidelines supplied with each drug as previously described (19). Laparotomy incisions were closed using full thickness running 3.0 nylon sutures and the rats woke up spontaneously. The rats had free access to food during the two weeks following surgery. After this, the second phase of study was conducted (Figure 1): the rats were sacrificed by decapitation and another laparotomy was performed. Adhesion scores of intra-abdominal adhesions were calculated macroscopically using the method proposed by Linsky et al. (5). With this method, the quality of adhesions and scores were determined grossly. All surgeries were performed by an executive surgeon.

The tissue biopsies were fixed in $10 \%$ neutral formalin buffer, passaged, processed, embedded in paraffin and sectioned serially at $5 \mu \mathrm{m}$. The sections were prepared by 
haematoxylin-eosin staining and examined under a light microscope. Every slide was examined three times and the mean of the results was reported. All scoring was done by a pathologist who did not have any information about the different groups of rats (Figure 2, 3). The quantity of adhesions was scored based on the percentage of adhesions in the total abraded area. The severity of adhesions was evaluated by the presence of neovascularisations and their quality (the formation of thin or thick vessel walls). Based on studies done by Ozturk et al.
(19), who studied 10 rats in each group, and Yuzbasioglu et al., who studied 6 rats in each of their groups, a sample size of 10 rats in each group was chosen. To compare the differences in means between study groups, one-way ANOVA tests were performed. If the $F$-test from ANOVA was significant $(P$-value $<0.05)$, then, we did the follow-up analysis using Tukey post-hoc analysis. All analyses were done using SPSS for Windows software. $P$-values of $<0.05$ were considered as statistically significant.

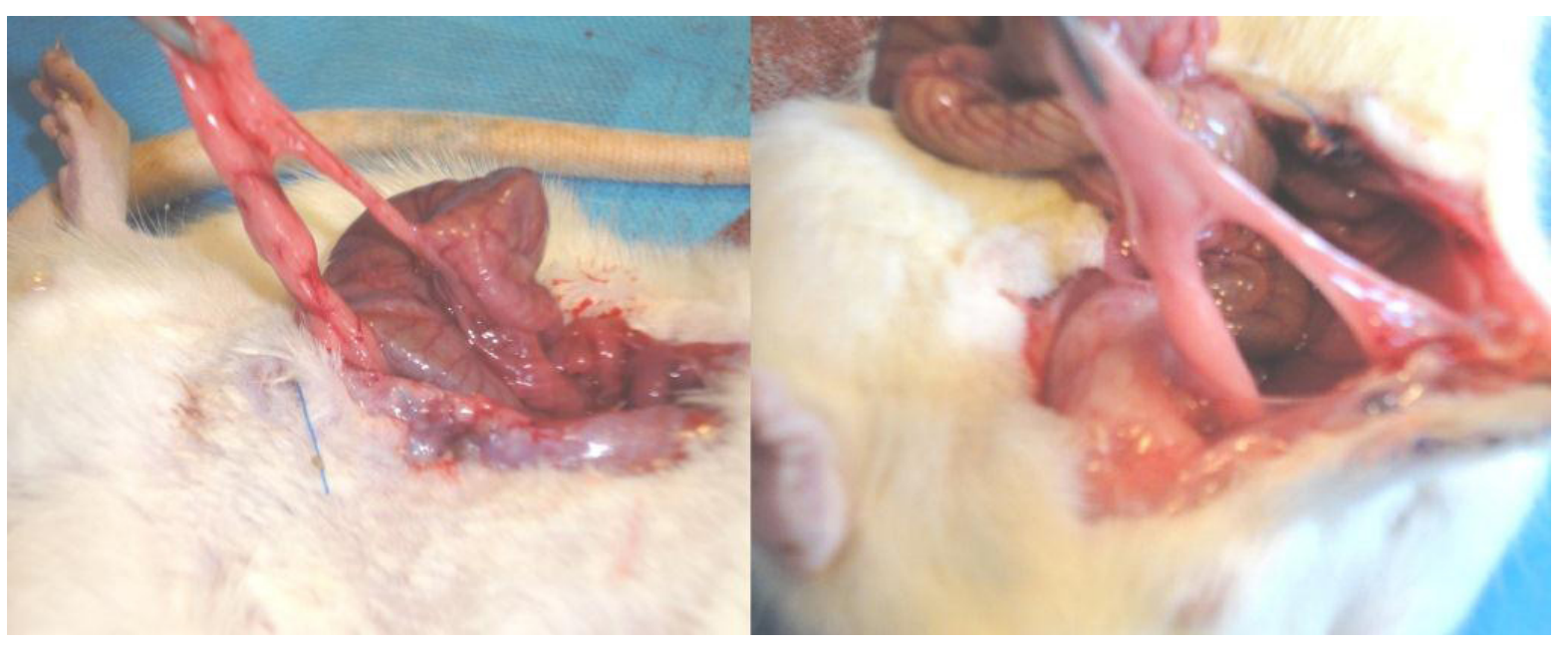

Figure 1. Abdominal adhesion band between small bowel and abdominal wall in rat $270 \mathrm{~mm} \times 109$ $\mathrm{mm}$



Figure 2. Severity of adhesions band scores based on Linsky scale (H\&E staining, $\times 400$ ). Proliferative phase of repair, characterised by migration and proliferation of fibroblasts associated with thin wall small vessels within score 3 
Original Article | Effect of lidocaine with bupivacaine on adhesion band

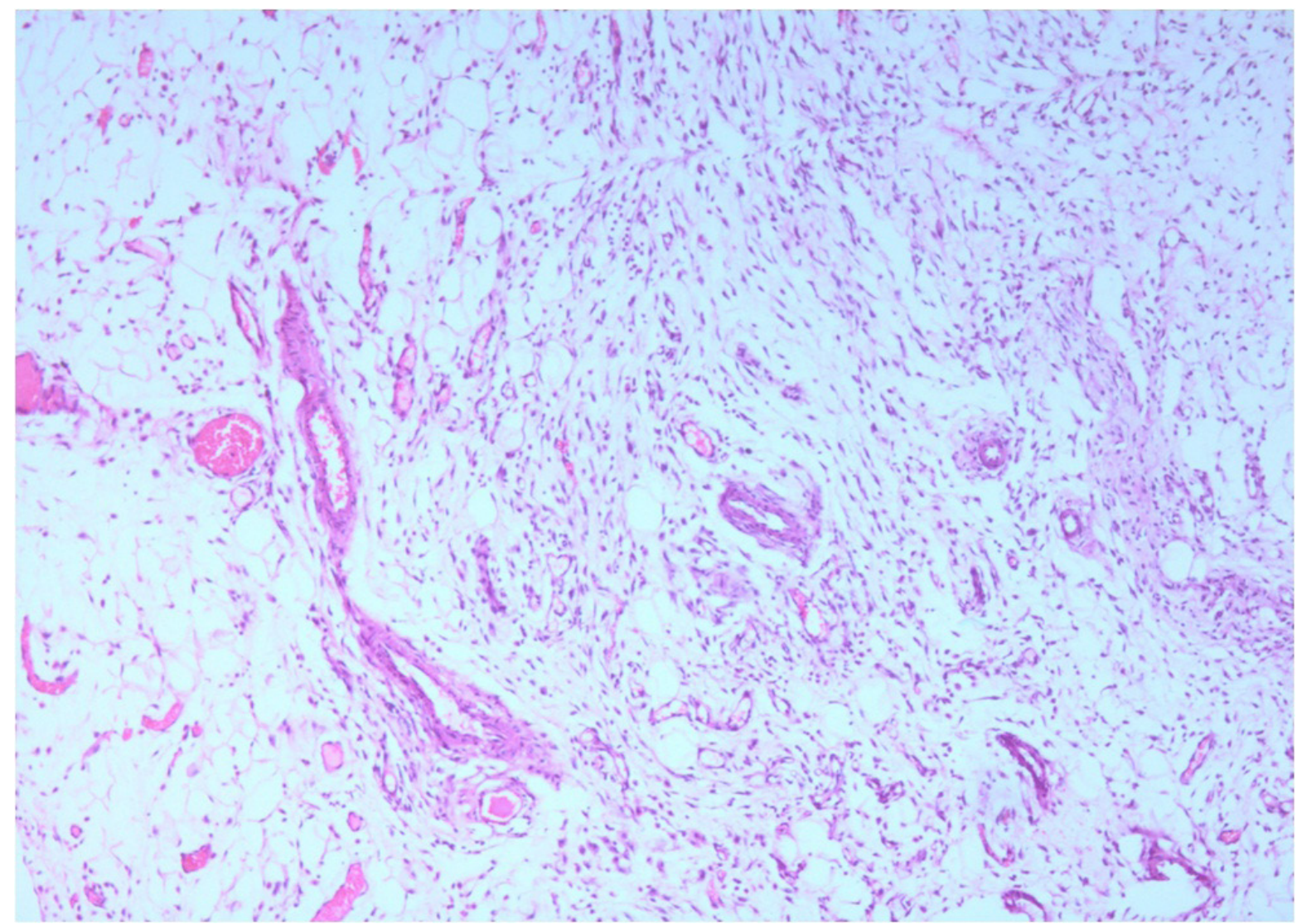

Figure 3. Quantity and severity of adhesions band scores based on Linsky scale (H\&E staining, $\times 100)$. Proliferative phase of repair, characterised by migration and proliferation of fibroblasts associated with thick wall small vessels within. Quantity and severity score 3 and 3, respectively

\section{Results}

Fifty female rats were included in this research project. They were divided into five groups, including control (no irrigation), normal saline, lidocaine $2 \%(3 \mathrm{mg} / \mathrm{kg})$, lidocaine $2 \%$ $(6 \mathrm{mg} / \mathrm{kg})$ and bupivacaine. Overall, 12 rats were not analysed in the study: 8 did not wake up following general anaesthesia and 4 of them died after surgery. Ultimately 38 rats were studied. Differences between the mean scores of quantity, quality, severity and scores of adhesions between the five groups, including control, normal saline, lidocaine $2 \%(3 \mathrm{mg} / \mathrm{kg})$, lidocaine $2 \%(6 \mathrm{mg} /$ $\mathrm{kg})$ and bupivacaine were significant $(P<0.05$; Table 1). The quantity of adhesions in the control group (2.14 \pm 0.69) was significantly higher than that in the lidocaine $6 \mathrm{mg} / \mathrm{kg}$ group $(1.4 \pm 0.7)$ and the bupivacaine group $(0.63 \pm 0.74)$. The quality of adhesions in the control group $(2.43 \pm 0.53)$ was significantly higher than that in the lidocaine $6 \mathrm{mg} / \mathrm{kg}$ group ( $0.6 \pm 0.89)$ and the bupivacaine group $(0.63 \pm 0.74)$. It was also significantly higher in the normal saline group $(2 \pm 1.07)$ than in the lidocaine $6 \mathrm{mg} / \mathrm{kg}$ group $(0.6 \pm 0.89)$ and bupivacaine group (0.63 \pm 0.74$)$. No significant difference was found between the severity of adhesions and the number of dead rats among the five groups. Adhesion scores in the control group $(5.14 \pm 1.07)$ were significantly higher than those in the lidocaine $6 \mathrm{mg} / \mathrm{kg}(1.2 \pm 1.79)$ and bupivacaine $(1.75 \pm 1.28)$ groups. 
Table 1. Comparing quantity, quality, severity and score of adhesion between groups

\begin{tabular}{|c|c|c|c|c|c|c|}
\hline Linsky scale & $\begin{array}{l}\text { Control } \\
\text { group } \\
\text { (1) }\end{array}$ & $\begin{array}{l}\text { Saline } \\
\text { group } \\
\text { (2) }\end{array}$ & $\begin{array}{c}\text { Lidocaine } \\
\text { 2\%(3 mg/kg) } \\
\text { Group } \\
\text { (3) }\end{array}$ & $\begin{array}{l}\text { Lidocaine } \\
2 \%(6 \mathrm{mg} / \mathrm{kg}) \\
\text { group } \\
\text { (4) }\end{array}$ & $\begin{array}{l}\text { Bupivacaine } \\
\text { group } \\
\text { (5) }\end{array}$ & P-value* \\
\hline $\begin{array}{l}\text { Quantity of } \\
\text { adhesions, } \\
(\text { Mean } \pm \text { SD) }\end{array}$ & $2.14 \pm 0.69$ & $1.63 \pm 0.92$ & $1.4 \pm 0.7$ & $0.6 \pm 0.89$ & $0.63 \pm 0.74$ & 0.003 \\
\hline $\begin{array}{l}\text { Severity of } \\
\text { adhesion, } \\
(\text { Mean } \pm \text { SD) }\end{array}$ & $2.67 \pm 0.51$ & $2 \pm 1.07$ & $0.5 \pm 0.84$ & $0.8 \pm 1.1$ & $1.25 \pm 1.28$ & 0.005 \\
\hline $\begin{array}{l}\text { Quality of } \\
\text { adhesions, } \\
(\text { Mean } \pm \text { SD) }\end{array}$ & $2.43 \pm 0.53$ & $2 \pm 1.07$ & $1.5 \pm 0.85$ & $0.6 \pm 0.89$ & $0.63 \pm 0.74$ & 0.001 \\
\hline $\begin{array}{l}\text { Score of } \\
\text { adhesions, } \\
(\text { Mean } \pm \text { SD) }\end{array}$ & $5.14 \pm 1.07$ & $3.63 \pm 1.92$ & $3 \cdot 3 \pm 1.34$ & $1.2 \pm 1.79$ & $1.75 \pm 1.28$ & 0.000 \\
\hline
\end{tabular}

* Analysis of variance is significant at level of 0.05

$P$-values for Mean differences from Tukey test: In quantity scale, $\operatorname{dif}_{1,4}: 0.016$, dif $f_{1,5}: 0.006$; In quality scale, dif ${ }_{1,4}$ : 0.006; dif ${ }_{1,5}: 0.002, \operatorname{dif}_{2,4}: 0.046$ dif $_{2,5}: 0.02 ;$ In Severity scale, dif $_{1,3}: 0.001, \operatorname{dif}_{1,4}^{1,4}: 0.002, \operatorname{dif}_{2,3}: 0.016 ;$ dif $_{2,4}: 0.006 ;$ In Score of adhesion, $\operatorname{dif}_{1,2}: 0.032, \operatorname{dif}_{1,3}: 0.028, \operatorname{dif}_{1,4}: 0.0001, \operatorname{dif}_{1,5}: 0.0002, \operatorname{dif}_{2,4}^{1,3}: 0.016 ; \operatorname{dif}_{3,4}^{1,4}: 0.02$.

\section{Discussion}

Results of the current study showed that the quantity of adhesions was significantly higher in the control group than in the lidocaine $2 \%(6$ $\mathrm{mg} / \mathrm{kg}$ ) and bupivacaine groups. The quality of adhesions in the control group was significantly higher in comparison with that in the lidocaine $2 \%$ (6 mg/kg), bupivacaine and normal saline groups, and higher in the lidocaine $6 \mathrm{mg} / \mathrm{kg}$ group than in the bupivacaine group. In contrast, Ozturk et al. (19) showed that the quality and quantity of adhesions in all groups were similar $(P>0.05)$. Perhaps one of the main reasons for this difference was the differences in dosages of the drugs. In the Ozturk study, it was suggested that low doses of the drugs could have caused the lack of success (19). For this reason, we doubled the doses in our study; in the current study lidocaine $6 \mathrm{mg} / \mathrm{kg}$ was used, whereas in Ozturk et al. (19) lidocaine was used at $3 \mathrm{mg} / \mathrm{kg}$. In the present study, similar to that of Ozturk et al., no significant difference was observed between the control group, the normal saline group and the lidocaine $3 \mathrm{mg} / \mathrm{kg}$ group. However, the present study showed that the incidence of adhesions can be reduced by increasing the dose of lidocaine. Further studies are needed to determine the dose of local anaesthetic needed to prevent the formation of adhesions. Despite similarities in the mechanisms of action of the anaesthetic drugs, bupivacaine reduced the quantity and quality of adhesions, whereas only high doses of lidocaine were able to do so. The fact that lidocaine is metabolised faster may explain this (21).

The results of this study also showed that adhesions scores in the control group were significantly higher than those in the lidocaine $6 \mathrm{mg} / \mathrm{kg}$ and bupivacaine groups. Yuzbasioglu et al. (18) also showed that adhesion scores in the EMLA group were significantly higher than those in the lidocaine and control groups. They concluded that the use of intra-peritoneal EMLA following intra-abdominal surgery significantly reduces the formation of adhesions without any effect on wound healing in bacterial peritonitis in rats. In addition, the present study showed that the severity of adhesions in the lidocaine $3 \mathrm{mg} / \mathrm{kg}$ and $6 \mathrm{mg} / \mathrm{kg}$ groups was lower than that in the control group, and in the lidocaine $3 \mathrm{mg} / \mathrm{kg}$ group, the severity was lower than in the normal saline group. Ozturk et al. showed that the adhesion intensity score was significantly lower with prilocaine and bupivacaine in comparison with other groups.

The mechanism of the anti-inflammatory effects of anaesthetic drugs is not yet understood. It has been suggested that local anaesthetics block neural activities locally and impair sensory, motor and autonomic neural functions 
Original Article | Effect of lidocaine with bupivacaine on adhesion band

$(21,22)$. It is likely that they block sodium membrane channels and reversibly stabilise cell membranes, reducing the inflammatory response in the areas of local anaesthetics administration (23). They also increase the activity of the fibrinolytic system, reduce levels of factor 8, plasminogen and alpha2-antiplasmin, and prevent platelet aggregation $(23,24)$. It is perhaps by this mechanism that local anaesthetic drugs exert their anti-inflammatory effects. The fact that the severity of adhesions and adhesion scores were significantly lower in the lidocaine and bupivacaine groups shows that using local anaesthetic drugs can reduce the quality, quantity and severity of intra-abdominal adhesions, but cannot prevent their formation. One reason for this may be that inflammation intensity may be related to adhesion severity without being the cause of the formation of adhesion (14). Therefore, local anaesthetic drugs reduce the intensity of adhesion by reducing inflammation, but do not prevent their formation.

This study's limitation is being experimental. Our main objective was to study the effects of these drugs on adhesions; their systemic absorption was not considered and their systemic effects were not studied. Therefore, it is recommended that in future studies, the toxicity of these drugs at a systemic level is examined. Also, in the current study, laparotomies were done at the end of the second week, when adhesions are the most severe. Therefore, we cannot comment on the long-term effects of local anaesthetics on intra-abdominal adhesions. Finally, the current study showed that the quantity and quality of adhesions and adhesion scores were significantly lower in the lidocaine $6 \mathrm{mg} / \mathrm{kg}$ and bupivacaine groups than in the control and saline groups. The severity of adhesions was also lower in the lidocaine 3 and $6 \mathrm{mg} / \mathrm{kg}$ groups. Furthermore, there was no significant difference in the numbers of rats that died across all five groups in the study. In future research, the effects should be studied over a longer period and the use of these methods in human research is not recommended until animal studies have been completed.

\section{Acknowledgement}

Writers of this article are thankful for the valuable cordial and dedicated cooperation of Velayat Clinical Research Development Unit of Velayat Hospital.

\section{Authors' Contributions}

Conception and design: HP, ZF

Drafting of the article: ZF

Final approval of the article: HP, ZF

Provision of study materials or patients: HS, ZF

Administrative, technical, or logistic support: FS-

$\mathrm{R}, \mathrm{MN}$

Collection and assembly of data: HS, AR

\section{Correspondence}

Dr Zahra Farahaninik

MD (Qazvin University of Medical Sciences), PhD (Qazvin University of Medical Sciences)

Assistant Professor of General Surgery

Velayat Clinical Research Development Unit

Velayat Hospital, 22 Bahman Blvd,

Qazvin, Iran.

P.O. Box 34719-76161

Tel: +982833760620 (669)

Fax: +982833790611

E-mail: dr.zfarahaninik@gmail.com

\section{References}

1. Ching SS, Muralikrishnan VP, Whiteley GS. Relaparotomy: a five-year review of indications and outcome. Int $J$ ClinPract. 2003;57(4):333337.

2. DeCherney AH, diZerega GS. Clinical problem of intraperitoneal postsurgical adhesion formation following general surgery and the use of adhesion prevention barriers. Surg Clin North Am. 1997;77(3):671-688. https://doi.org/10.1016/ Soo39-6109(05)70574-0

3. Yilmazlar T, Kaya E, Gurpinar E, Emiroglu H. Efficacy of tenoxicam on intra-abdominal adhesion prevention in a rat model. $J$ Int Med Res. 1996;24(4):352-357. https://doi. org/10.1177/030006059602400406

4. Liebman SM, Langer JC, Marshall JS, Collins SM. Role of mast cells in peritoneal adhesion formation. Am J Surg. 1993;165(1):127-130. https://doi.org/10.1016/Sooo2-9610(05)80415-5

5. Linsky CB, Diamond MP, Cunningham T, Constantine B, DeCherney AH, diZerega GS. Adhesion reduction in the rabbit uterine horn model using an absorbable barrier, TC-7. $J$ Reprod Med. 1987;32(1):17-20. 
6. Ar'Rajab A, Dawidson I, Sentementes J, Sikes P, Harris R, Mileski W. Enhancement of peritoneal macrophages reduces postoperative peritoneal adhesion formation. $J$ Surg Res. 1995;58(3):307-312. https://doi.org/10.1006/ jsre.1995.1048

7. Boland GM, Weigel RJ. Formation and prevention of postoperative abdominal adhesions. $J$ Surg Res. 2006;132(1):3-12. https://doi. org/10.1016/j.jss.2005.12.002

8. Gupta S, Jain PK. Low-dose heparin in experimental peritonitis. Eur Surg Res. 1985;17(3):167-172. https://doi. org/10.1159/000128463

9. Turkcapar AG, Ozarslan C, Erdem E, Bumin C, Erverdi N, Kutlay J. The effectiveness of low molecular weight heparin on adhesion formation in experimental rat model. Int Surg. 1995;80(1):92-94

10. Tayyar M, Basbug M. The effects of intraperitonealpiroxicam and low molecular weight heparin in prevention of adhesion reformation in rat uterine horn. Res Exp Med (Berl). 1999;198(5):269-275. https://doi. org/10.1007/s004330050110

11. Thompson JN, Whawell SA. Pathogenesis and prevention of adhesion formation. Br J Surg. 1995;82(1):3-5. bjs.1800820103.

12. Lin $\mathrm{HF}$, Wu CY, Wu MC, Chou TH, Lin GS, Yen $\mathrm{ZS}$, et al. Hypothermia decreases post-operative intra-abdominal adhesion formation. Am J Surg. 2014;208(3):419-424. https://doi.org/10.1016/j. amjsurg.2013.10.028

13. Yildiz MK, Okan L, Dursun N, Bas G, Alimoglu O, Kaya B , et al. Effect of orally administered simvastatin on prevention of postoperative adhesion in rats. Int $J$ Clin Exp Med. 2014;7(2):405-410.

14. Karakas DO, Yigitler C, Gulec B, Kucukodaci Z, Ipcioglu OM, Akin ML. Comparison of 4\% icodextrin and omega 3 fatty acids in prevention of peritoneal adhesions. Indian $J$ Surg. 2014;76(3):181-186. https://doi.org/10.1007/ s12262-012-0661-y

15. Dinarvand P, Farhadian S, Seyedjafari E, Shafiee A, Jalali A, Sanaei-rad P, et al. Novel approach to reduce postsurgical adhesions to a minimum: administration of losartan plus atorvastatin intraperitoneally. J Surg Res. 2013;181(1):91-98. https://doi.org/10.1016/j.jss.2012.05.035

16. Dinarvand P, Hashemi SM, Seyedjafari E, Shabani I, Mohammadi-Sangcheshmeh A, Farhadian S, et al. Function of poly (lactic-co-glycolic acid) nanofiber in reduction of adhesion bands. $J$ Surg Res. 2012;172(1):e1-e9. https://doi. org/10.1016/j.jss.2011.10.014

17. Reijnen MM, Bleichrodt RP, van Goor $H$. Pathophysiology of intra-abdominal adhesion and abscess formation, and the effect of hyaluronan. Br J Surg. 2003;90(5):533-541. https://doi. org/10.1002/bjs.4141

18. Yuzbasioglu MF, Ezberci F, Senoglu N, Ciragil P, Tolun FI, Oksuz H, et al. Intraperitoneal EMLA (lidocaine/prilocaine) to prevent abdominal adhesion formation in a rat peritonitis model. Bratisl Lek Listy. 2008;109(12):537-543.

19. Ozturk E, Yilmazlar A, Berhuni S, Yilmazlar T. The effectiveness of local anesthetics in preventing postoperative adhesions in rat models. Tech Coloproctol. 2010;14(4):337-340. https:// doi.org/10.1016/j.yebeh.2013.04.01910.1007/ s10151-010-0644-6.

20. Nassiri-Asl M, Moghbelinejad S, Abbasi E, Yonesi F, Haghighi MR, Lotfizadeh M, et al. Effects of quercetin on oxidative stress and memory retrieval in kindled rats. Epilepsy and Behavior. 2013;3:151-155. https://doi.org/10.1016/j. yebeh.2013.04.019

21. Becker DE, Reed KL. Essentials of local anesthetic pharmacology. Anesth Prog. 2006;53(3):98-108; quiz 109. doi:10.2344/00033006(2006)53\%5B98:EOLAP\%5D2.o.CO;2

22. Ruetsch YA, Boni T, Borgeat A. From cocaine to ropivacaine: the history of local anesthetic drugs. Curr Top Med Chem. 2001;1(3):175-182. https:// doi.org/10.2174/1568026013395335

23. Hollmann MW, Durieux ME. Local anesthetics and the inflammatory response: a new therapeutic indication? Anesthesiology. 2000;93(3):858875. https://doi.org/10.1097/ 00000542200009000-00038

24. Borg T, Modig J. Potential anti-thrombotic effects of local anaesthetics due to their inhibition of platelet aggregation. Acta Anaesthesiologica Scandinavica. 1985;29(7):739-742. https://doi. org/10.1111/j.1399-6576.1985.tbo2292.x 